\title{
Lanthanum Probe Studies of Cellular Pathophysiology Induced by Hypoxia in Isolated Cardiac Muscle
}

\author{
Karen P. Burton, Herbert K. Hagler, Gordon H. Templeton, \\ James T. Willerson, and L. Maximilian Buja, Departments of \\ Pathology, Physiology, and Internal Medicine, Southwestern Medical \\ School, University of Texas Health Science Center at Dallas, Dallas, \\ Texas 75235
}

A B S T RACT This study was undertaken to evaluate directly the relationship between evolution of irreversible myocardial injury induced by hypoxia in an isolated papillary muscle preparation and the development of pathophysiological alterations related to severely impaired membrane function. An ionic lanthanum probe technique was employed as a cytochemical marker to monitor the progression of cellular injury, and data from this cytologic technique were correlated with ultrastructure and measurements of contractile parameters in a total of 67 muscles subjected to control conditions or to graded intervals of hypoxia with or without reoxygenation. Marked depression of developed tension and rate of tension development occurred after $30 \mathrm{~min}$ of hypoxia. Contractile function showed significant recovery with reoxygenation after $1 \mathrm{~h}$ and $15 \mathrm{~min}$ of hypoxia but remained depressed when reoxygenation was provided after 2 or $3 \mathrm{~h}$ of hypoxia. Examination by transmission and analytical electron microscopy (energy dispersive X-ray microanalysis) revealed lanthanum deposition only in extracellular regions of control muscles and muscles subjected to $30 \mathrm{~min}$ of hypoxia. After hypoxic intervals of over $1 \mathrm{~h}$, abnormal intracytoplasmic and intramitochondrial localization of lanthanum were detected. After $1 \mathrm{~h}$ and $15 \mathrm{~min}$ of hypoxia, abnormal intracellular lanthanum accumulation was associated with only minimal ultrastructural

Data from this study were presented at the 49th Scientific Sessions of the American Heart Association Meeting, Miami Beach, Fla., 15-18 November 1976 (1976. Circulation. 54 [Suppl. II]: II-115. [Abstr.]), the 74th Annual Meeting of the American Association of Pathologists, Toronto, Canada, 11-15 March 1977 (1977. Am. J. Pathol. 86: 43a.

[Abstr.]), and the First Annual Meeting of the American Section of the International Society for Heart Research, Pasadena, Calif., 13-14 May 1977.

Dr. Willerson is an Established Investigator of the American Heart Association.

Received for publication 17 December 1976 and in revised form 20 June 1977. evidence of injury; muscle provided reoxygenation after $1 \mathrm{~h}$ and $15 \mathrm{~min}$ of hypoxia showed improved ultrastructure and did not exhibit intracellular lanthanum deposits upon exposure to lanthanum during the reoxygenation period. After 2 to $3 \mathrm{~h}$ of hypoxia, abnormal intracellular lanthanum accumulation was associated with ultrastructural evidence of severe muscle injury which persisted after reoxygenation. Thus, the data support the conclusion that cellular and membrane alterations responsible for abnormal intracellular lanthanum deposition precede the development of irreversible injury but evolve at a transitional stage in the progression from reversible to irreversible injury induced by hypoxia in isolated feline papillary muscles.

\section{INTRODUCTION}

Previous studies of hypoxic and ischemic myocardial injury have identified several factors which could be responsible for initiation of the irreversible phase of myocardial injury (1). These factors include prolonged acidosis $(2)$, release of lysosomal enzymes $(3,4)$, mitochondrial failure $(5,6)$, and certain types of plasma membrane alterations, including severe functional abnormalities in membrane permeability and structural defects in membrane integrity $(1,7)$. Nevertheless, definitive information has not been obtained regarding the mechanism(s) responsible for transition from reversible to irreversible myocardial injury. The present study was undertaken to evaluate directly the relationship between initiation of irreversibility and development of pathophysiological alterations related to severely impaired membrane function. To study this relationship, an ionic lanthanum probe technique was employed as a cytochemical marker of the progression of cellular injury induced by graded intervals of hypoxia with or without reoxygenation in isolated papillary muscles $(8-13)$. Development of the lanthanum probe technique was based on previous studies which 
have characterized the response of normal myocardium to lanthanum (14-21). The major physiological effect of lanthanum, a trivalent ion with electrochemical properties similar to calcium (14), is excitation-contraction uncoupling associated with displacement of calcium from superficial binding sites (15-19). Several ultrastructural studies have shown that lanthanum selectively binds to the basal lamina-plasma membrane complex and is not visualized ultrastructurally within normal cardiac muscle cells (17-21). These previous studies indicate that abnormal ultrastructural localization of lanthanum intracellularly can serve as a cytochemical marker of pathophysiological alterations in injured myocardium. In the present study, an isolated papillary muscle preparation was employed so that direct evaluation could be made of the interrelationships between cellular alterations resulting in abnormal lanthanum deposition and the evolution of derangements in ultrastructural and contractile parameters resulting from progressive myocardial injury.

\section{METHODS}

67 papillary muscles were obtained from the right ventricles of cats anesthetized with sodium pentobarbital $(30 \mathrm{mg} / \mathrm{kg})$. Mean cross-sectional area of the muscles was $0.92 \pm 0.05$ $\mathrm{mm}^{2}$ SEM. Three muscles were excised and tied on toothpicks to maintain normal stretch and were fixed directly for electron microscopic study. 64 muscles were excised and placed in a bath chamber containing a physiological salt solution, $\mathrm{pH} 7.3-7.4$, consisting of $140 \mathrm{mM} \mathrm{NaCl}, 4 \mathrm{mM} \mathrm{KCl}$, $2.5 \mathrm{mM} \mathrm{CaCl}_{2} \cdot 2 \mathrm{H}_{2} \mathrm{O}, 1 \mathrm{mM} \mathrm{MgCl}{ }_{2} \cdot 6 \mathrm{H}_{2} \mathrm{O}, 18 \mathrm{mM}$ glucose, and $3 \mathrm{mM} N$-2-hydroxyethylpiperazine- $N^{\prime}$-2-ethane sulfonic acid (Hepes, Calbiochem, San Diego, Calif.) (16). Osmolality of the solution was 291 mosmol. The solution was bubbled with $100 \% \mathrm{O}_{2}$ and kept at a constant temperature of $29^{\circ} \mathrm{C}$. Muscles were held between spring loaded clips with one clip attached to a tension transducer (UC2 Statham Instruments, Inc., Oxnard, Calif.) and were stimulated with impulses $20 \%$ above threshold and of $5 \mathrm{~ms}$ duration and at 5-s intervals through platinum electrodes placed parallel to the long axis of the muscle $(11,12)$. A 1 -h stabilization period preceded each intervention. During this time, the length of the muscle, at which maximal tension was developed ( $\mathrm{L} \max ),{ }^{1}$ and the threshold for the muscle were determined. The parameters of resting tension (RT), developed tension (DT), the rate of tension development $(+\mathrm{dT} / \mathrm{dt})$, and time to peak tension (TPT) were recorded on a Hewlett-Packard direct writer (model 7700, Hewlett-Packard Co., Palo Alto, Calif.). Contractile parameters were measured in all 64 muscles, and results were evaluated statistically with Student's twotailed paired $t$ test; differences were considered to be significant when $P<0.05$. Hypoxia was produced by removal of the $100 \% \mathrm{O}_{2}$ from the system and by bubbling the salt solution with $100 \% \mathrm{~N}_{2}$. The $\mathrm{PO}_{2}$ of the solution declined from approximately $500 \mathrm{~mm} \mathrm{Hg}$ (control) to a value of $<40 \mathrm{~mm} \mathrm{Hg}$

${ }^{1}$ Abbreviations used in this paper: DT, developed tension; $+\mathrm{dT} / \mathrm{dt}$, rate of tension development; $\mathrm{L}$ max, length of muscle at which maximal tension is developed; RT, resting tension; STEM, scanning transmission electron micrograph; TEM, transmission electron micrograph, TPT, time to peak tension. within $10 \mathrm{~min}$; the $\mathrm{pH}$ remained in the range of 7.3 to 7.4 throughout the experiments. Of the 64 muscles, 18 controls were maintained in oxygenated medium for $1-3 \mathrm{~h}$ after initial stabilization; 19 muscles were subjected to hypoxia for $30 \mathrm{~min}-3 \mathrm{~h}$ after initial stabilization, and 27 muscles were subjected to hypoxia for variable intervals and then reoxygenated. 8 control, 11 hypoxic, and 23 reoxygenated muscles were exposed to lanthanum (La) by replacing the standard Hepes solution with a similar solution containing $5 \mathrm{mM} \mathrm{LaCl}$ for the last $30 \mathrm{~min}-1 \mathrm{~h}$ in the bath (19). Reoxygenation studies involved reoxygenation with $100 \% \mathrm{O}_{2}$ for $30 \mathrm{~min}$ followed by an additional hour in oxygenated medium containing La. Long term reoxygenation studies of $5 \mathrm{~h}$ before La exposure also were performed.

Electron microscopic examination was performed on 14 control, hypoxic, or reoxygenated muscles not exposed to $\mathrm{La}$ and on $\mathbf{4 2}$ control, hypoxic, or reoxygenated muscles exposed to La. Fixation for electron microscopy was initiated by immersion of the muscles in a modified, half-strength Karnovsky's fixative, i.e., a mixture of $2 \%$ paraformaldehyde and $2.5 \%$ glutaraldehyde in $0.1 \mathrm{M}$ cacodylate buffer ( $\mathrm{pH}$ 7.4), while the muscles were still held between the clips at $\mathrm{L}$ max. After initial fixation, the muscles were removed from the clips and were divided into small samples which were given additional fixation in the aldehyde solution $(20,22)$. The fixatives did not contain La. Three muscles obtained directly and not subjected to in vitro study also were fixed by immersion in aldehyde solution. Fixation was followed by a buffer wash of $0.2 \mathrm{M}$ sucrose in $0.1 \mathrm{M}$ cacodylate. Some pieces of each muscle were postfixed in $1 \% \mathrm{OsO}_{4}$ in $0.1 \mathrm{M}$ cacodylate (pH 7.4), and other samples for analytical electron microscopy were left unosmicated. Muscles were then dehydrated in a graded series of alcohols and propylene oxide and embedded in epon-araldite (22).

Sections approximately $1 \mu \mathrm{m}$ thick were cut, stained with toluidine blue, and examined by light microscopy. After study of the $1-\mu \mathrm{m}$ sections, representative areas from superficial subendocardial sites were selected for ultramicrotomy. Only superficial sites within $100-200 \mu \mathrm{m}$ from the endo-

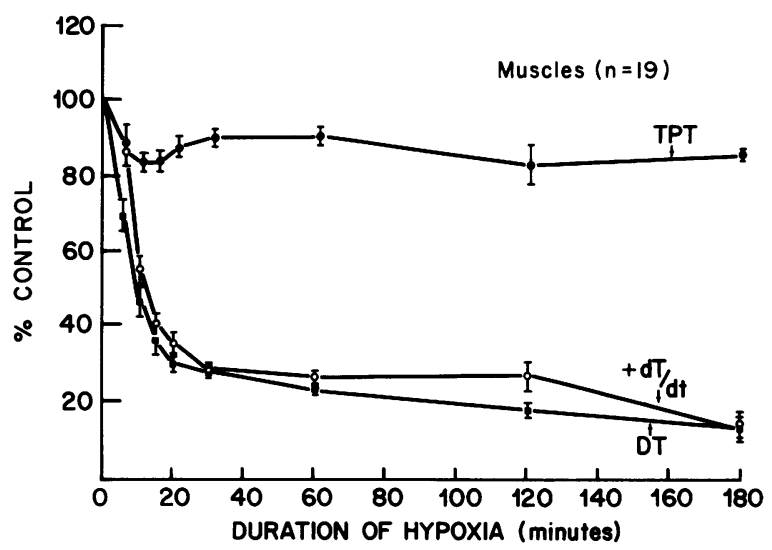

FIGURE 1 Effect of hypoxia on contractile parameters of isolated cat right ventricular papillary muscles. The data were obtained before the introduction of $5 \mathrm{mM}$ lanthanum chloride and are expressed as per cent of the control value obtained for each muscle at the end of 1-h stabilization period before the onset of hypoxia. All data points (mean $\pm \mathrm{SE}$ ) are significantly different $(P<0.05)$ from control values. Hypoxia induced rapid and marked depression in DT and $+\mathrm{dT} / \mathrm{dt}$ but resulted in only mild depression in TPT. 
cardial surface were chosen to evaluate regions within maximal exposure to La. For routine transmission electron

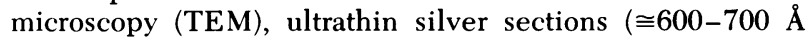
thick) of osmicated tissue were cut, mounted on copper grids, and stained with uranyl acetate and lead citrate or left unstained. Sections for scanning transmission electron microscopy (STEM) were cut in the gold range (1000-1200 $\AA$ ) from both osmicated and unosmicated tissue, left unstained and carbon coated. Sections were viewed with a JEOL 100C transmission electron microscope equipped with a JEOL high resolution scanning attachment (JEOL USA, Medford, Mass.) (ASID) and a Kevex $30 \mathrm{~mm}^{2}, 158 \mathrm{eV}$ resolution, lithium-drifted silicon, energy dispersive X-ray detector (Kevex corp., Burlingame, Calif.) placed within $20 \mathrm{~mm}$ of the specimen through the objective pole piece (23). Analyses were performed for $30 \mathrm{~s}$, and X-ray counts were processed through a Tracor Northern NS 880 multichannel analyzer (Tracor Northern, Middleton, Wis.) operated at $20 \mathrm{eV} / \mathrm{channel}$ (23). The tissue was examined for elemental content of various mitochondrial densities and for the presence of La in extracellular and intracellular locations $(23,24)$. Documentation of the presence of La and other elements in the spectra was determined by a multiple least squares regression analysis using reference spectra prepared from single crystal samples $(23,25)$. The analyses of spectra were performed with the DEC PDP 11/05 computer-based Tracor Northern NS 880 unit. The limit of elemental detection of energy dispersive X-ray spectroscopy has been reported to be 1 ag (25).

\section{RESULTS}

Contractile parameters. Isolated cat papillary muscles placed in a muscle bath with an oxygenated medium continued to contract with stimulation and showed no significant change in contractile parameters. With the onset of hypoxia, contractile parameters began declining immediately (Fig. 1). Significant changes (expressed as percentage of control values $\pm \mathrm{SE})(P<0.05)$ were noted in DT, $+\mathrm{dT} / \mathrm{dt}$, and TPT. After $30 \mathrm{~min}$ of hypoxia, DT and $+\mathrm{dT} / \mathrm{dt}$ had declined to $<30 \%$ of normal, whereas TPT showed a mild decrease (Fig. 1). Resting tension (RT) fell to $79.0 \%$ of normal at $1 \mathrm{~h}$ and then became mildly increased at 2 and $3 \mathrm{~h}$. After exposure of control muscles to La, DT dropped $\cong 75 \%$ within a few beats and then declined more gradually to virtually zero over 5-15 min. The marked depression of DT was associated with a delayed gradual elevation of RT. Hypoxic muscles developed similar changes in DT and RT upon exposure to La, but cessation of DT, which was previously depressed by hypoxia, occurred after only 1-2 min.

Reoxygenation data showed that muscles reoxygenated after $1 \mathrm{~h}$ and $15 \mathrm{~min}$ of hypoxia generally showed recovery of contractile parameters, whereas after $2-3 \mathrm{~h}$ of hypoxia little recovery was evident. Reoxygenation after $1 \mathrm{~h}$ and $15 \mathrm{~min}$ of hypoxia resulted in significant partial improvement in DT (Fig. 2) and $+\mathrm{dT} / \mathrm{dt}$ after $30 \mathrm{~min}$ and returned to levels close to control values after $5 \mathrm{~h}$ of reoxygenation. With muscles exposed to hypoxia for 2-3 hours, DT and

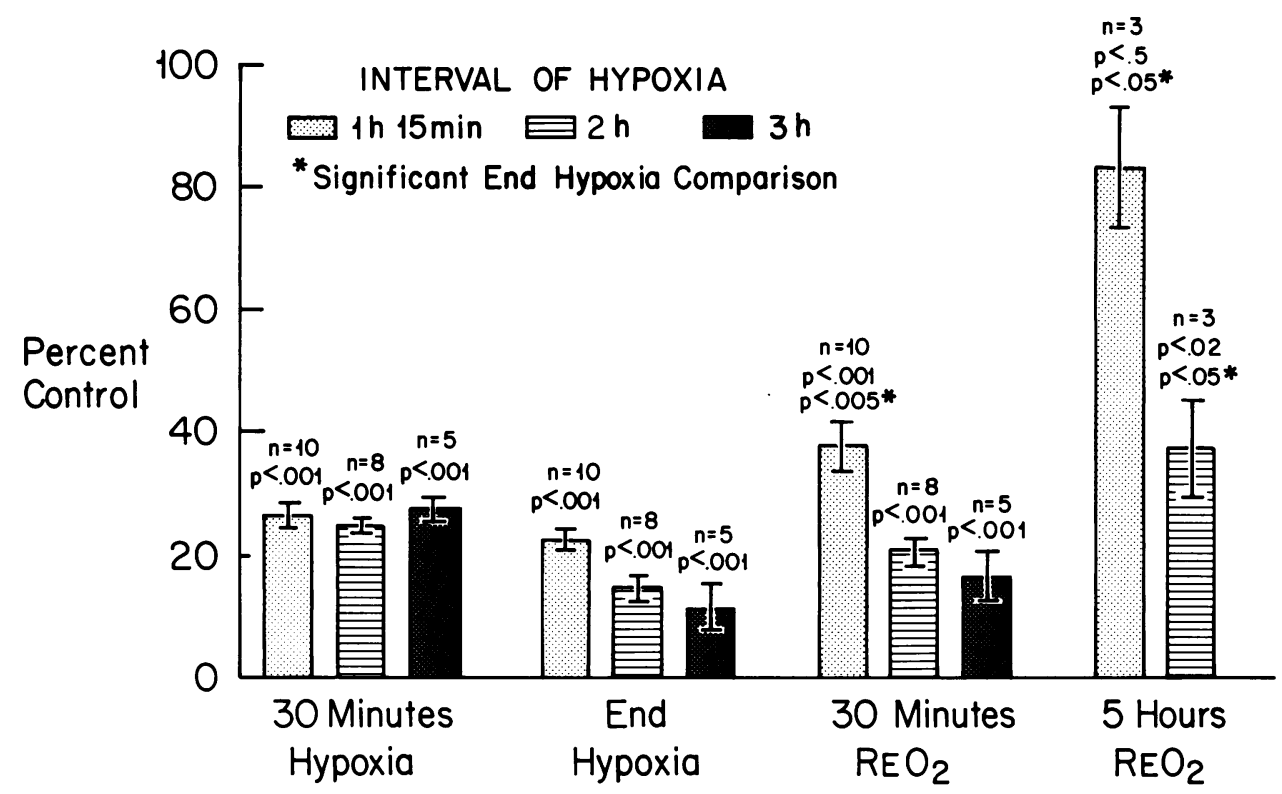

FIGURE 2 Effect of reoxygenation on the contractile parameter of developed tension after $1 \mathrm{~h}$ and $15 \mathrm{~min}, 2 \mathrm{~h}$, and $3 \mathrm{~h}$ of hypoxia. Data are expressed as per cent of control values (mean $\pm \mathrm{SE}$ ) at various intervals of hypoxia or reoxygenation. Results of statistical comparisons with control values are shown for each experimental measurement and significant comparisons with end hypoxia values are also included for the reoxygenation data. Reoxygenation after $1 \mathrm{~h}$ and 15 min of hypoxia resulted in significant partial recovery of DT at $30 \mathrm{~min}$ and a return to control values after $5 \mathrm{~h}$. Reoxygenation after $2-3 \mathrm{~h}$ of hypoxia did not result in significant recovery. 
$+\mathrm{dT} / \mathrm{dt}$ remained markedly depressed after $30 \mathrm{~min}$ of reoxygenation (Fig. 2). Muscles exposed to $2 \mathrm{~h}$ of hypoxia and then reoxygenated for $5 \mathrm{~h}$ showed significant, mild improvement in DT, but the change in $+\mathrm{dT} / \mathrm{dt}$ was less and not statistically significant compared to end hypoxia values. Both DT and $+\mathrm{dT} / \mathrm{dt}$, however, remained significantly below control values even after prolonged reoxygenation of the 2-h hypoxic muscles (Fig. 2). TPT was found to be significantly depressed during hypoxia and significantly increased after $30 \mathrm{~min}$ of reoxygenation for muscles exposed to 1 $h$ and 15 min-2 $h$ of hypoxia; after prolonged reoxygenation, TPT again approached control values. Reoxygenation of muscles hypoxic for $3 \mathrm{~h}$ was not associated with the typical prolongation of TPT observed after reoxygenation of the 1-2-h hypoxic muscles. The mild elevation in RT observed after 2-3 hours of hypoxia was reversed upon reoxygenation.

Ultrastructure of control, oxygenated muscles. Muscles fixed after 1-4 $\mathrm{h}$ in the bath appeared similar to those muscles fixed directly after excision and showed normal ultrastructure as previously described (26). In muscles exposed to La, electron-dense deposits consistent with La deposition were apparent only in extracellular locations. These electron-dense deposits were observed in stained and unstained sections of osmicated or unosmicated material (Figs. 3 and 4). The La deposits were localized to the basal lamina (glycocalyx) of the plasma membranes and within adjacent pinocytotic vesicles, intercalated discs, and $\mathrm{T}$ tubules.

Small dense granules with typical features of normal

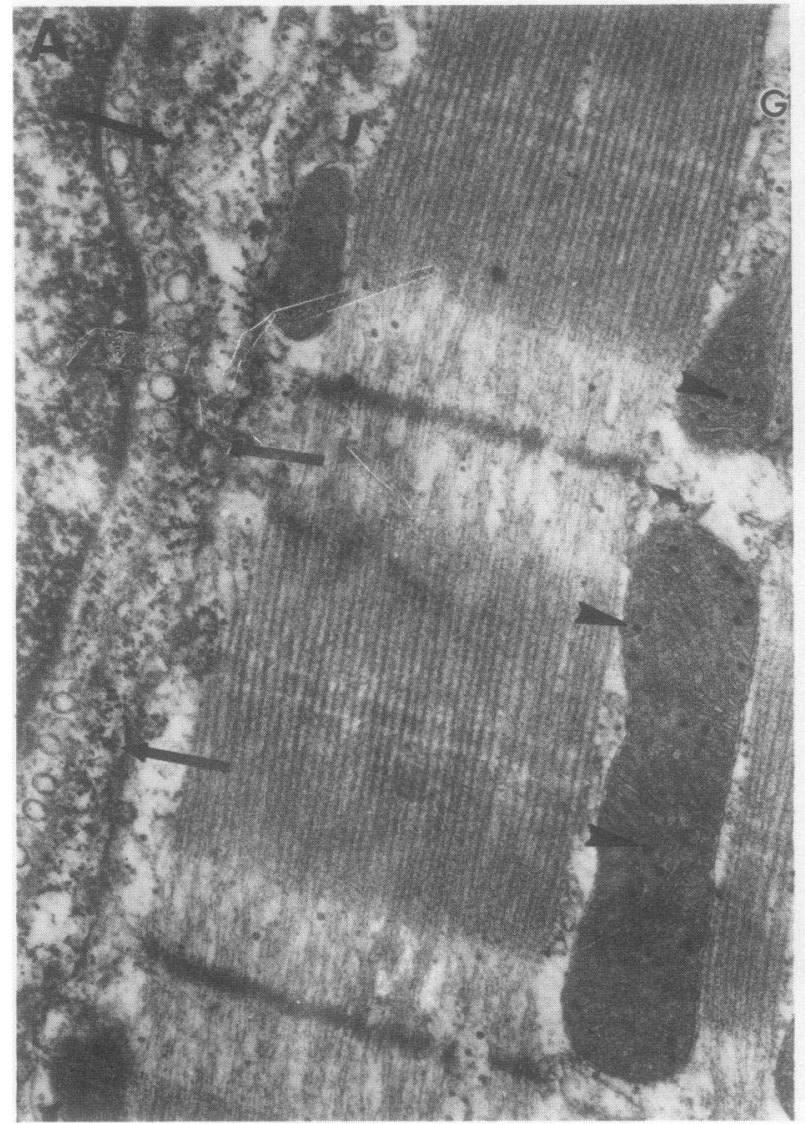

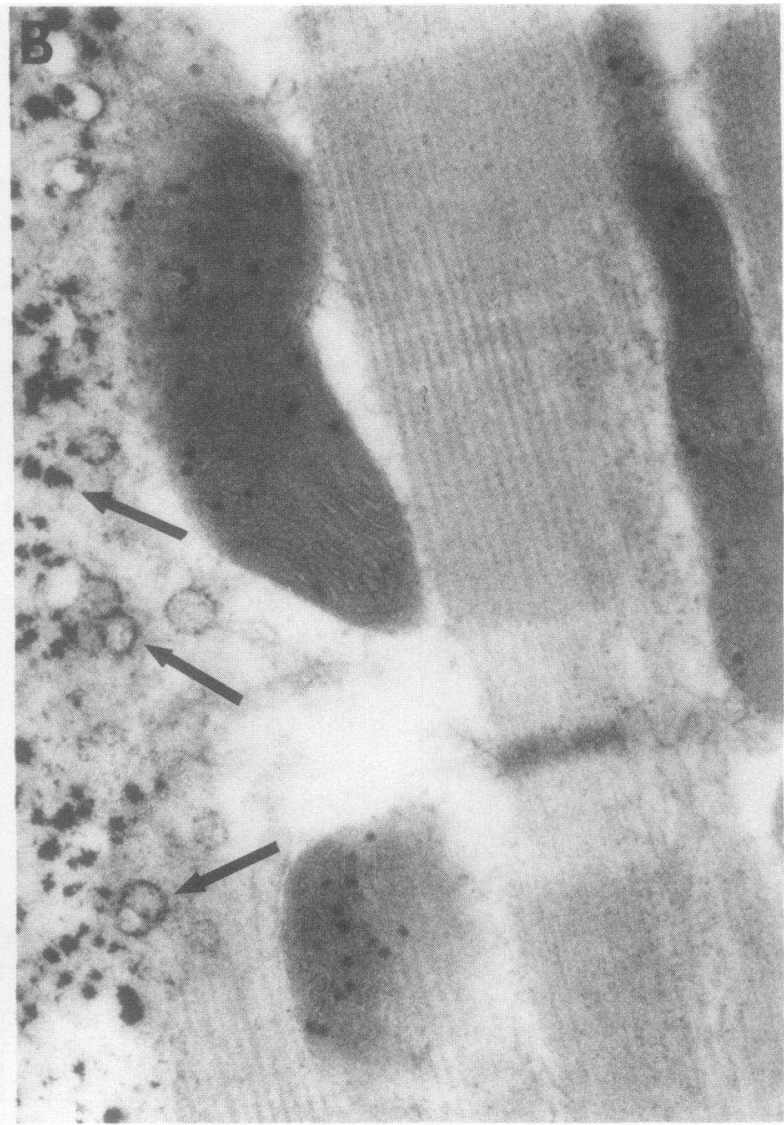

Figure 3 Control, oxygenated muscle. (A) TEM of a stained osmicated section of muscle maintained for a total of $4 \mathrm{~h}$ in oxygenated medium and exposed to $5 \mathrm{mM}$ La during the last hour. The tissue is compact and free of edema. The muscle cell contains glycogen granules $(G)$. The myofibrils are fixed at $\mathrm{L}$ max and exhibit prominent $\mathrm{A}, \mathrm{I}$, and $\mathrm{Z}$ bands. The mitochondria contain numerous, small, electron-dense, normal matrix granules (arrowheads). Electron-dense inclusions consistent with La deposits (arrows) are limited to the extracellular space and are concentrated along the glycocalyx. $\times 26,400$. (B) TEM of an unstained osmicated section of muscle maintained for $4 \mathrm{~h}$ in oxygenated medium and exposed to $5 \mathrm{mM}$ La during the last hour. Aggregates of electron-dense material consistent with La deposits (arrows) are better appreciated along the plasma membrane and in pinocytotic vesicles. Electron-dense, normal, mitochondrial matrix granules also are prominent. $\times 40,000$. 

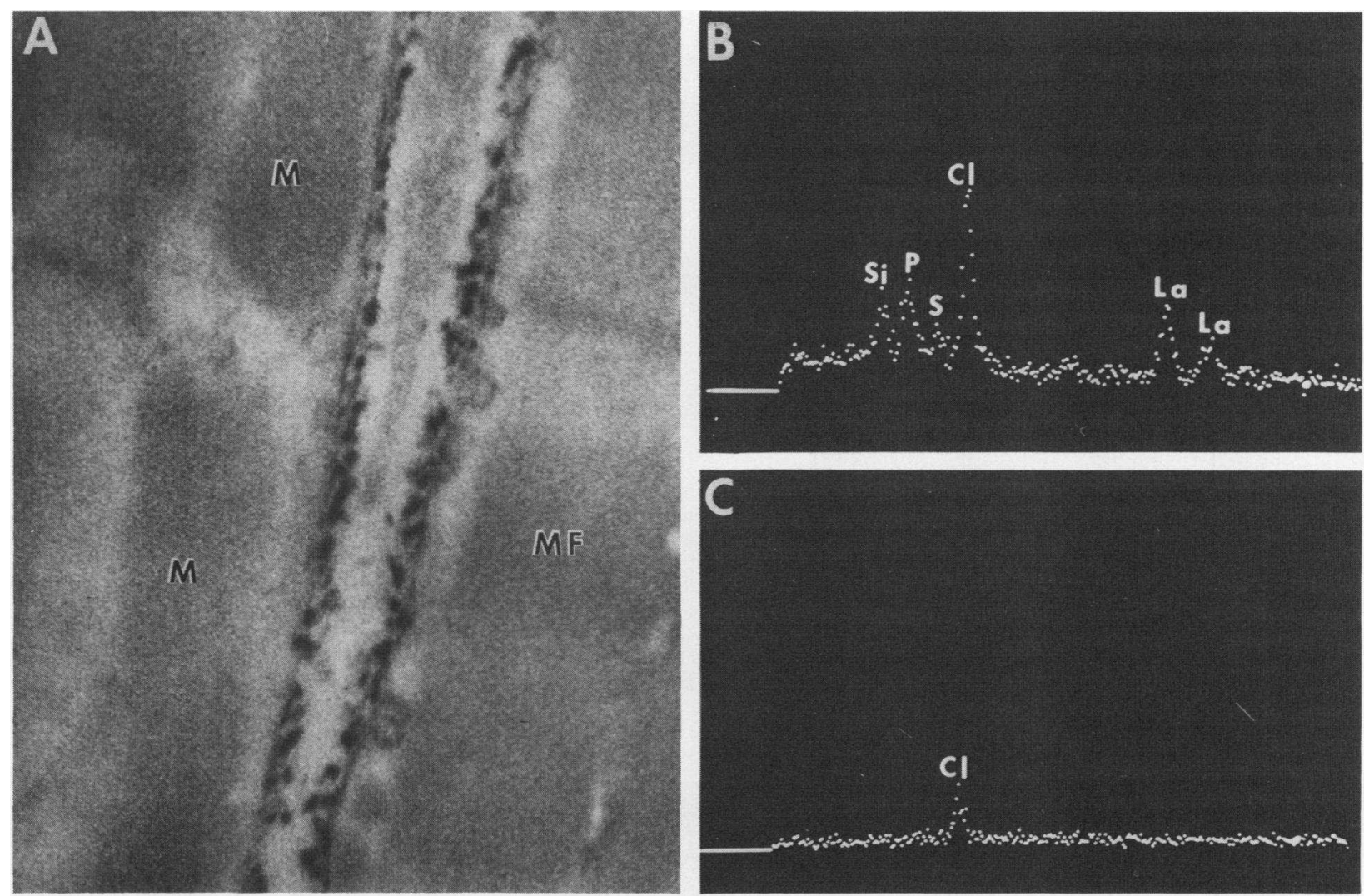

FIGURE 4 Control, oxygenated muscle. (A) STEM of an unstained, unosmicated section of muscle exposed to $5 \mathrm{mM}$ La. Myofibrils (MF) and mitochondria (M) are identified. Electrondense deposits are limited to the glycocalyx. The mitochondrial matrix granules no longer exhibit selective electron density in this unosmicated section; compare with Fig. $3 . \times 39,300$. (B) Typical X-ray spectrum obtained from microarea over the plasma membrane shows that the electron dense deposits contain lanthanum, phosphorus, and, possibly, trace amounts of sulphur. The chlorine peak is from the embedding medium and the silicon peak is related to contamination during analysis. (C) Typical X-ray spectrum obtained from a microarea within a muscle cell mitochondrion shows no detectable lanthanum.

mitochondrial matrix granules $(13,26)$ were prominent in control papillary muscles whether or not the muscles were exposed to La (Fig. 3). Electron density of the matrix granules was apparent in unstained as well as stained sections of osmicated tissue examined by routine TEM or STEM (Fig. 3). Selective electron density of the granules, however, was diminished or not apparent in unstained sections of unosmicated tissue examined by STEM (Fig. 4).

Analytical electron microscopy revealed prominent La peaks ( $\mathrm{L} \alpha 4.65 \mathrm{keV}$ and $\mathrm{L} \beta 5.04 \mathrm{keV}$ ) in the electron-dense deposits along the plasma membranes and other extracellular sites (Fig. 4). Areas of La deposition also were associated with prominent phosphorus peaks (Ka $2.01 \mathrm{keV})$. Other elements detected, including chlorine and silicon, were related to the embedding medium and instrumentation employed (2325). No foci of intracellular La accumulation were de- tected. In particular, no La peaks were obtained from normal mitochondria or myofibrils (Fig. 4).

Ultrastructure of hypoxic muscles. After 15-30 min of hypoxia, muscle cells showed generally well preserved ultrastructure (Fig. 5). Although focal mild edema, focally decreased glycogen content, and an occasional increase in lipid droplets were observed, the most striking alteration was an apparent widespread loss of the normal mitochondrial dense osmiophilic granules. In many areas, however, small round matrix structures corresponding to the granules could still be identified, and some of these structures exhibited focal electron density around their peripheries (Fig. 5). These findings were observed in osmicated sections of tissue with or without exposure to La. In muscles hypoxic for up to $30 \mathrm{~min}$, La deposits remained confined to the extracellular space (Fig. 5).

With intervals of $1 \mathrm{~h}$ and $15 \mathrm{~min}-3 \mathrm{~h}$ of hypoxia, 

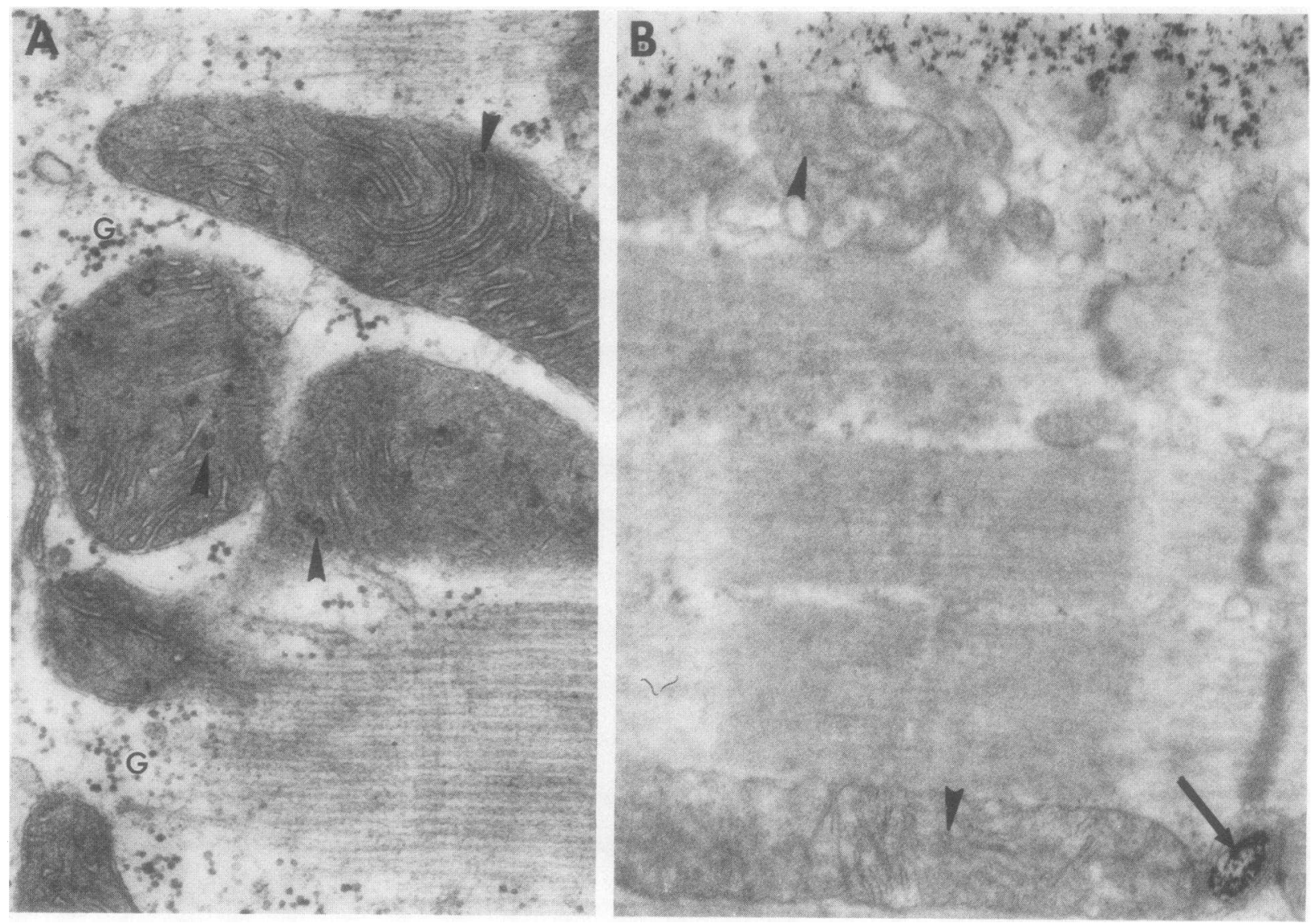

FIgURE 5 Muscle subjected to 15-30 min of hypoxia. (A) TEM of a stained, osmicated section of muscle rendered hypoxic for $15 \mathrm{~min}$ and not exposed to $\mathrm{La}$. The muscle cell is not edematous and contains abundant glycogen (G). The normal mitochondrial matrix granules show decreased osmiophilia with increased electron density remaining only at the periphery (arrowheads); compare with Fig. 3. $\times 41,600$. (B) TEM of an unstained osmicated section of muscle subjected to 30 min of hypoxia in medium containing $5 \mathrm{mM} \mathrm{La}$. Electron-dense deposits of La remain confined to the extracellular space and are localized to the glycocalyx of the plasma membrane and within a $\mathrm{T}$ tubule (arrow). The normal matrix granules (arrowheads) of the mitochondria show a complete absence of selective electron density; compare with Fig. 3 . $\times 34,100$.

intracellular as well as extracellular deposition of $\mathrm{La}$ was detected by TEM and confirmed by analytical electron microscopy (Figs. 6-8). Intracellular La deposition in muscle cells occurred in the form of small, granular to spicular electron-dense deposits. The La deposits were localized mainly within the I bands in close proximity to the $\mathrm{Z}$ bands of myofibrils and in the mitochondria over the inner mitochondrial membranes and in the adjacent matrix (inner mitochondrial compartment) (Fig. 6). Analytical electron microscopy confirmed the presence of La and phosphorus in the abnormal intracellular inclusions (Fig. 7).

FIgURE 6 Hypoxic muscle. (A) TEM of an unstained, osmicated section of muscle subjected to a total of $1 \mathrm{~h}$ and $15 \mathrm{~min}$ of hypoxia with $5 \mathrm{mM} \mathrm{La}$ in the medium for the final $1 \mathrm{~h}$. The muscle cell shows only slight edema but contains extensive electron-dense deposits consistent with La deposition in myofibrillar I and $\mathrm{Z}$ bands (arrows), around lipid droplets ( $L$ ), and in mitochondria (M). $\times 27,600$. (B) TEM of an unstained, osmicated section of muscle subjected to $2 \mathrm{~h}$ of hypoxia. The muscle cell shows slight cytoplasmic and mitochondrial swelling. Electron dense deposits of $\mathrm{La}$ are present in the interstitial space and similar, smaller deposits (arrows) are present in the matrices of the mitochondria. $\times 43,200$. (C) TEM of a stained, osmicated section of a muscle exposed to $2 \mathrm{~h}$ of hypoxia. La deposits are located over the inner mitochondrial membrane (arrows) and in the adjacent matrix (arrowhead). $\times 94,400$. 


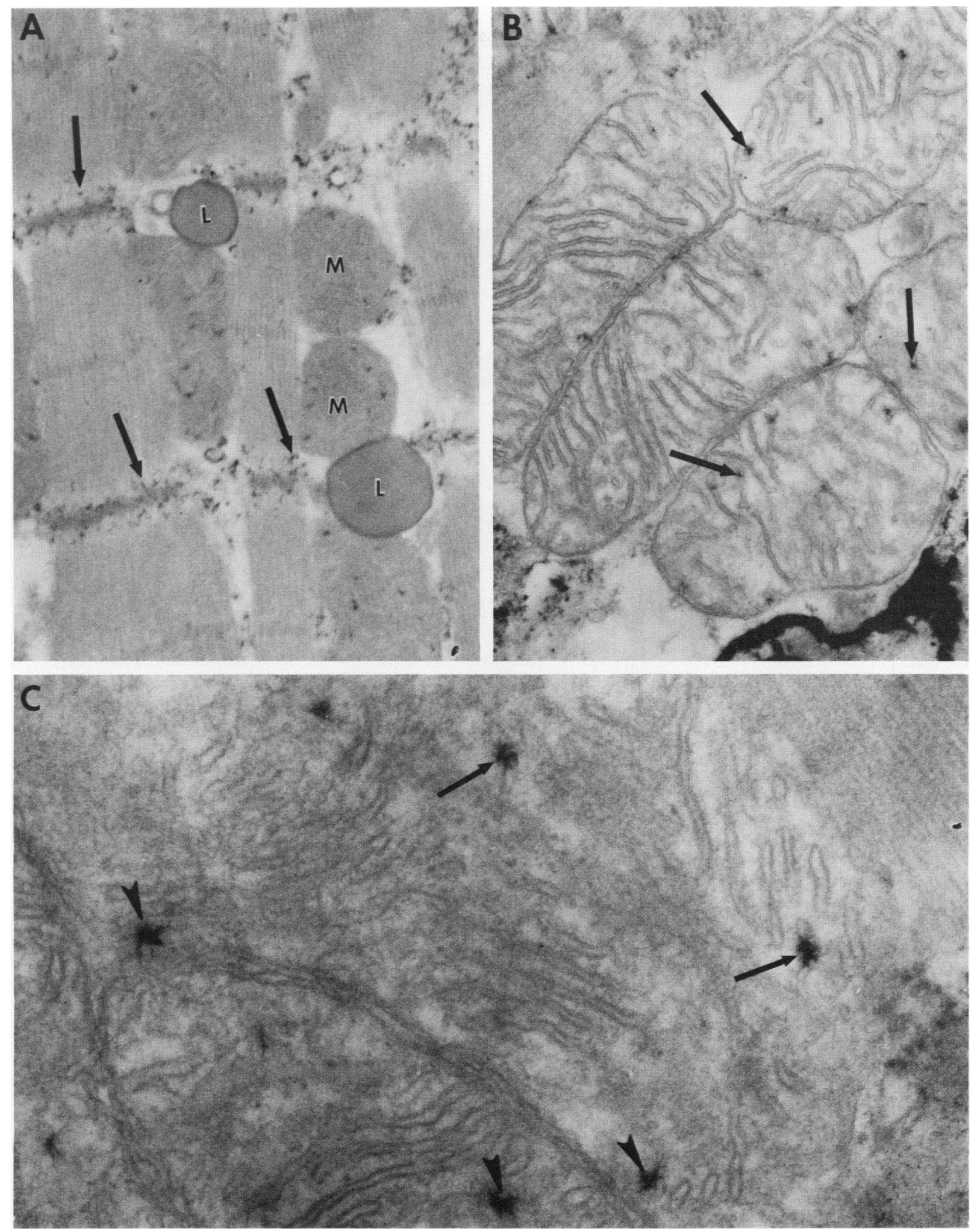



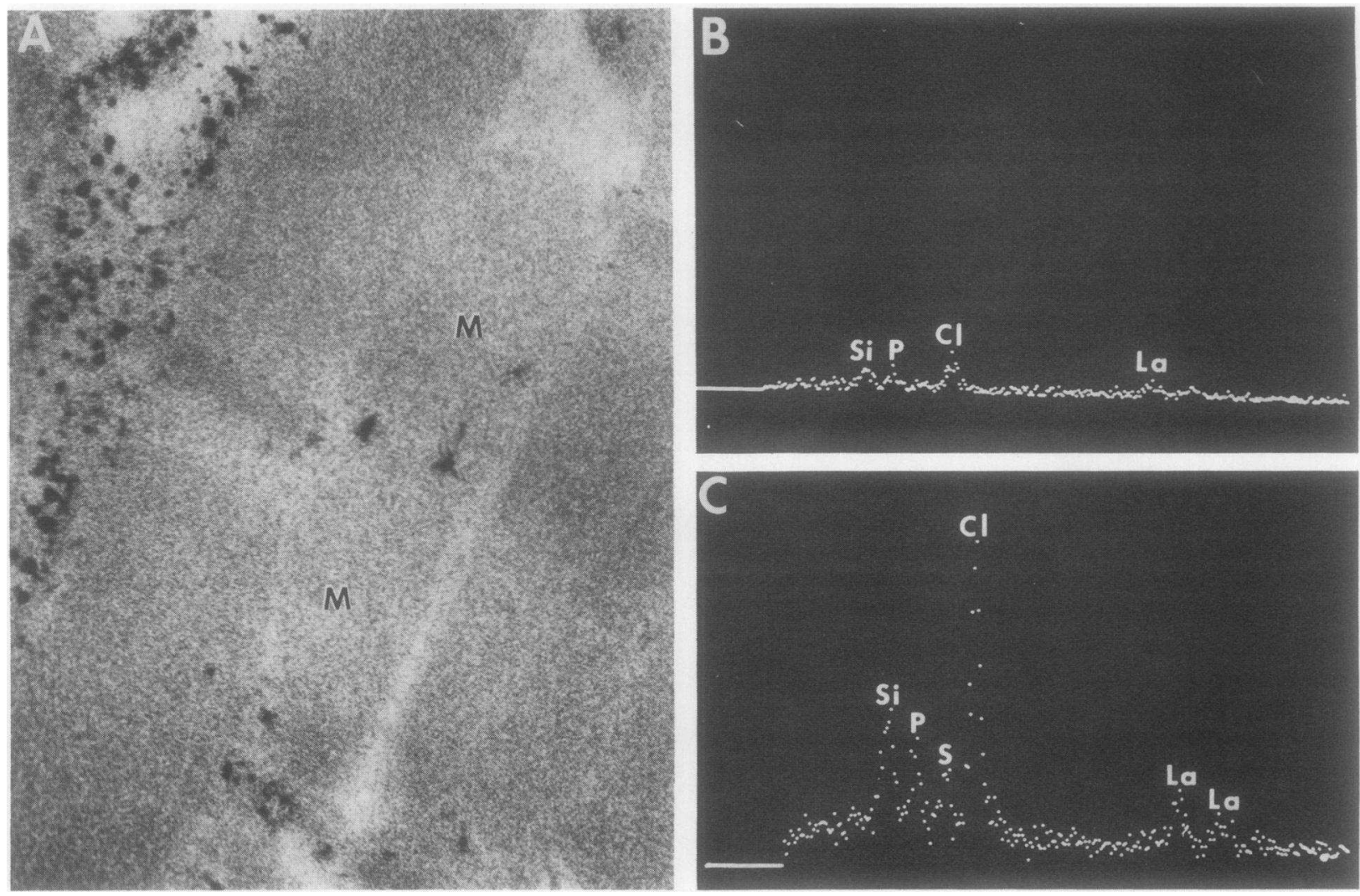

FIGURE 7 Hypoxic muscle. (A) STEM of an unstained, unosmicated section of hypoxic muscle exposed to $5 \mathrm{mM}$ La showing the inherent electron density of deposits along the plasma membrane and within the mitochondria (M). $\times 39,900$. (B) X-ray spectrum obtained from an individual mitochondrial inclusion confirming the presence of small but statistically significant lanthanum and phosphorus peaks ( $1 \sigma$ confidence limit). The other elements present are related to the factors described in Fig. 3. (C) X-ray spectrum obtained by summing the data from 10 mitochondrial inclusions confirms the consistent presence of lanthanum and phosphorus in these inclusions $(2 \sigma$ confidence limit).

After 1-2 h of hypoxia, most muscle cells had wellpreserved ultrastructure and exhibited minimal ultrastructural evidence of injury in the form of focal edema, focal decrease in glycogen content, and loss of selective osmiophilia of the normal mitochondrial matrix granules (Figure 6). These muscle cells were essentially similar in ultrastructural appearance to muscle cells subjected to shorter intervals of hypoxia. These muscle cells, however, typically showed variable degrees of cytoplasmic and intramitochondrial $\mathrm{La}$ deposition, but had structurally intact plasma and mitochondrial membranes (Figures 6 and 7). After $2 \mathrm{~h}$ of hypoxia, some muscle cells exhibited more severe damage characterized by generalized mild-to-moderate edema, severe-to-total glycogen depletion, focal mitochondrial swelling, and focal appearance of typical amorphous matrix (flocculent) densities in mitochondria (Fig. 8). These flocculent mitochondrial densities have been shown to represent definite ultra- structural evidence of irreversible damage (5-7). After $3 \mathrm{~h}$ of hypoxia, many muscle cells showed severe damage with marked edema, myofibrillar disruption, contraction bands, and numerous flocculent mitochondrial densities. Intracellular La deposition in the severely damaged muscle cells observed after 2-3 h was more variable and frequently was less prominent than in muscle cells with less severe structural damage. It should be noted, however, that minimally injured muscle cells with abundant intracellular $\mathrm{La}$ also were present in samples obtained after 2-3 h of hypoxia.

Ultrastructure of reoxygenated muscles. Reoxygenation after $1 \mathrm{~h}$ and $15 \mathrm{~min}$ of hypoxia resulted in an improvement of cellular ultrastructure, including a reappearance of the normal osmiophilic matrix granules, an increase in glycogen content, and a decrease in edema (Fig. 9); prominent accumulation of lipid droplets also was observed in several muscles. These 
muscles did not exhibit intracellular La deposits after exposure to La during the reoxygenation period, and no La peaks were obtained from intracellular areas by analytical electron microscopy.

Muscle reoxygenated after $2 \mathrm{~h}$ of hypoxia showed improvement in ultrastructural appearance of some superficial subendocardial muscle cells including a return of normal mitochondrial granules and a slight increase in glycogen content; however, the majority of muscle cells still exhibited damage in the form of edema, glycogen depletion, mitochondrial alterations, and abnormal intracellular lanthanum accumulation (Fig. 10).

The ultrastructural alterations which occurred during $3 \mathrm{~h}$ of hypoxia generally persisted or progressed after reoxygenation.

\section{DISCUSSION}

The present study using an ionic lanthanum probe technique has demonstrated that cellular and membrane alterations responsible for abnormal intracellular lanthanum deposition precede the development of ultrastructural and physiological evidence of irreversible injury, but evolve at a transitional stage in the progression from reversible to irreversible injury induced by hypoxia in isolated feline papillary muscle. It must be noted that findings regarding hypoxic in-
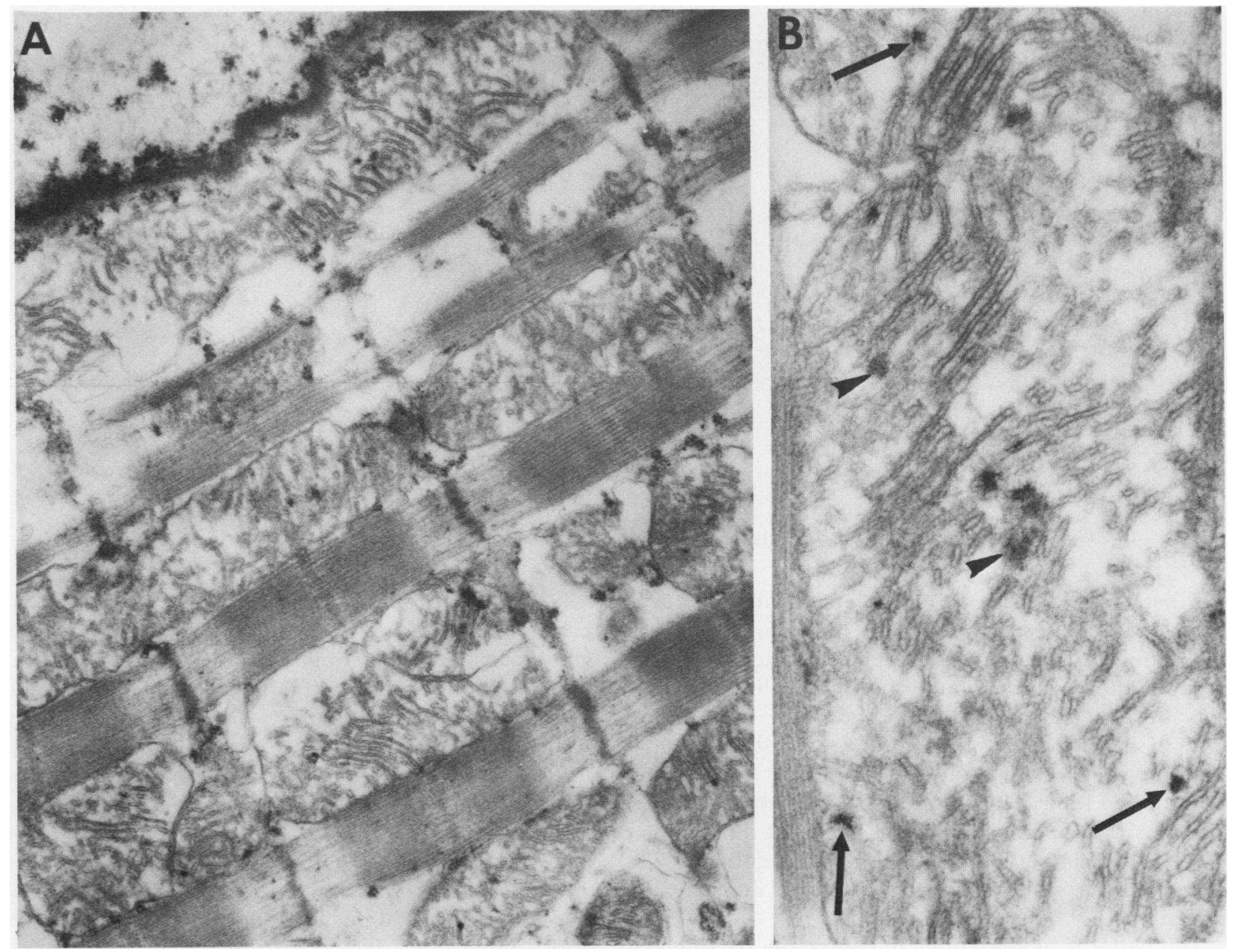

FIgURE 8 (A) TEM of an unstained, osmicated section of muscle subjected to a total of $2 \mathrm{~h}$ of hypoxia with La in the medium during the final $1 \mathrm{~h}$. The muscle cell shows prominent clumping of nuclear chromatin, marked cytoplasmic and mitochondrial edema, and small, pleomorphic mitochondrial inclusions. $\times 24,550$. (B) This mitochondrion taken from the same section of muscle as in A contains both amorphous matrix (flocculent) densities (arrowheads) characteristic of irreversibly injured cells and electron-dense inclusions consistent with La deposition (arrows). $\times 45,000$. 


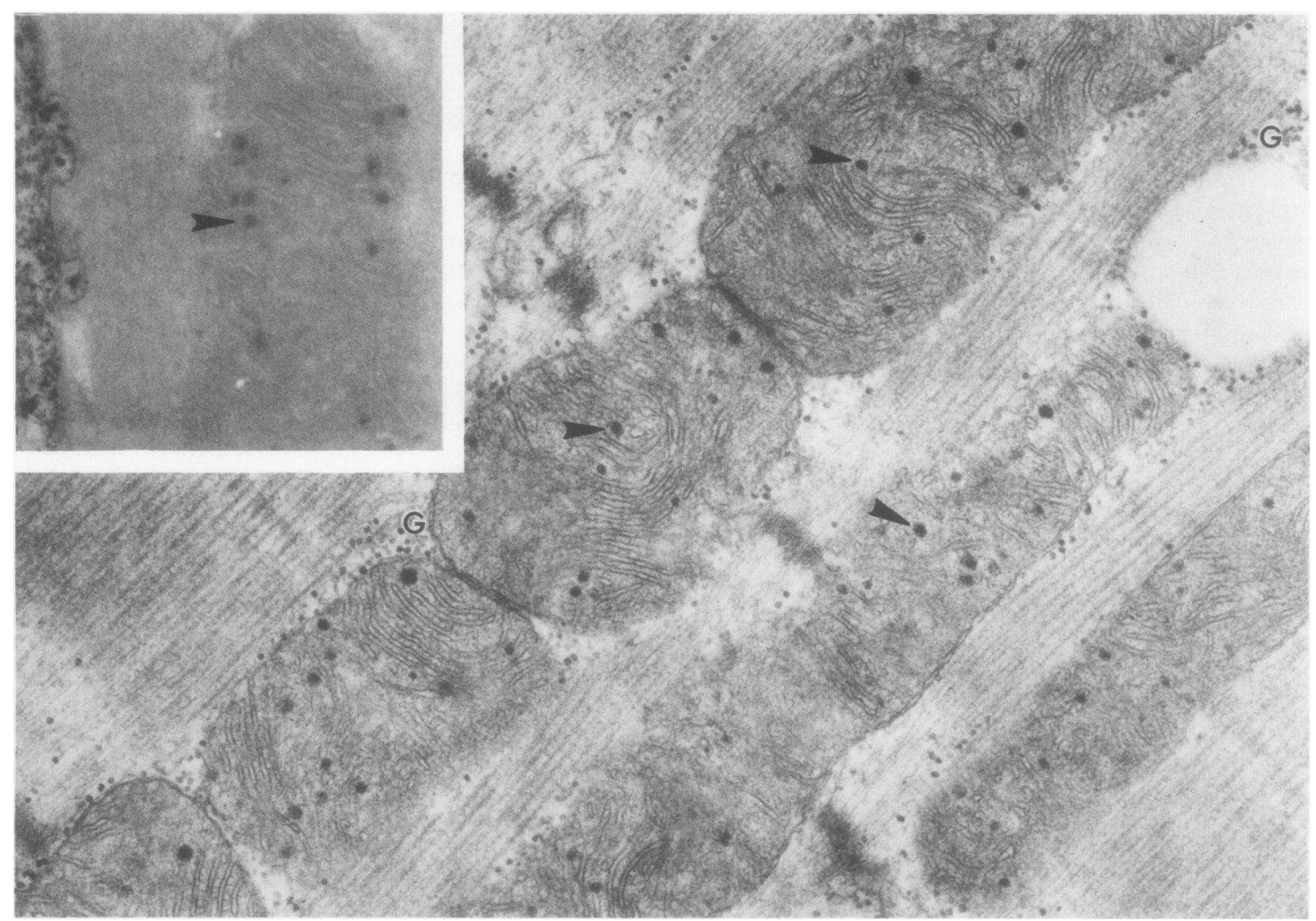

FIGURE 9 TEM of stained, osmicated section of muscle reoxygenated for $1 \frac{1}{2} \mathrm{~h}$ after $1 \mathrm{~h}$ and 15 min of hypoxia. The muscle was exposed to La during the last hour of reoxygenation. The tissue shows an improvement of cellular ultrastructure, a return of the normal mitochondrial granules (arrowheads), and an increase in glycogen (G) content. No La is evident intracellularly. $\times 40,000$. Insert of unstained, osmicated section shows a return of the normal matrix granules (arrowhead) and an absence of La over myofibrils or in mitochondria. $\times 49,400$.

jury may not be directly applicable to ischemic injury, because ischemic injury involves multiple factors, inincluding hypoxia, substrate depletion, acidosis, and accumulation of lactate and other metabolites (1). Observations in the present study, however, provide information regarding the evolution of cellular pathophysiology in response to one important component of ischemic injury. Furthermore, interpretation of the data was not complicated by the effects of reflow phenomena which would be associated with delivery of a cytochemical probe such as lanthanum in an ischemia model.

The patterns of alterations in contractile parameters in isolated papillary muscle observed in the present study in response to hypoxia and reoxygenation were similar to those reported previously $(8-10,12,13)$. We observed a rapid decrease in contractile parameters in response to hypoxia, as previously described by other investigators $(8-10,12,13)$. We also observed delayed recovery of muscles upon reoxygenation after
$1 \mathrm{~h}$ and $15 \mathrm{~min}$ of hypoxia and failure of significant recovery after $2-3 \mathrm{~h}$ of hypoxia. The latter findings were consistent with a more rapid progression of injury than previously reported for isolated feline muscle (8-10). Differences in progression of hypoxic injury in the present and previous studies may be related to differences in the preparations, including use of Hepes buffer in the present study rather than bicarbonate which would cause precipitation of lanthanum. Major emphasis, however, was not on the exact timing of the progression of contractile and ultrastructural alterations but on the relationship between reversible and irreversible changes in these parameters and development of abnormal lanthanum accumulation.

The present study extends previous work utilizing probe techniques for the evaluation of altered cellular pathophysiology in muscle injury. In vitro localization of colloidal lanthanum nitrate (average particle size $40 \AA$ ) in muscle cells has been documented in rat cremaster muscle sampled $2 \mathrm{~h}$ after thermal injury (27) 
and in canine cardiac muscle sampled $3 \frac{1}{2} \mathrm{~h}$ after coronary occlusion (28). After intravenous injection, horseradish peroxidase ( $\mathrm{mol} \mathrm{w} \mathrm{40,000)}$ has been localized in damaged muscle cells of the rat at various intervals after administration of high doses of sympathomimetic amines or temporary coronary occlusion $(29,30)$. Intracellular localization of colloidal lanthanum or horseradish peroxidase was detected in severely damaged or frankly necrotic muscle cells with structural membrane defects as well as in variable numbers of minimally damaged or normal-appearing muscle cells (27-30). Deposition of colloidal lanthanum $(27,28)$ or horseradish peroxidase $(29,30)$ in or around the outer membranes of mitochondria was frequently noted, but intramitochondrial localization of the tracers was observed only in mitochondria with severe structural damage. Plasma proteins also have been utilized as tracers of altered membrane integrity in cardiac muscle after coronary occlusion $(31,32)$ and in skeletal muscle after exposure to lecithinase C (33).
Albumin (mol wt 40,000) was detected in muscle cells after $1 \mathrm{~h}$ of injury and larger plasma proteins, such as fibrinogen, after longer intervals of injury (31-33). The latter studies, however, employed light microscopic immunofluorescence techniques and did not include correlation with extent of ultrastructural alteration. In the present study, the probe employed was an ionic species with a hydrated radius of $3.1 \AA$ (14) and, therefore, was significantly smaller than the other probes described above. Furthermore, exposure to ionic lanthanum was carried out before chemical fixation in contrast to the colloidal lanthanum studies.

With regard to the significance of abnormal intracellular lanthanum accumulation, available information suggests that this phenomenon may result from the interaction of a complex of pathophysiological alterations. One factor appears to be increased permeability to lanthanum of the plasma membrane-basal lamina complex induced by prolonged hypoxic injury. Although exposure to lanthanum produces alterations

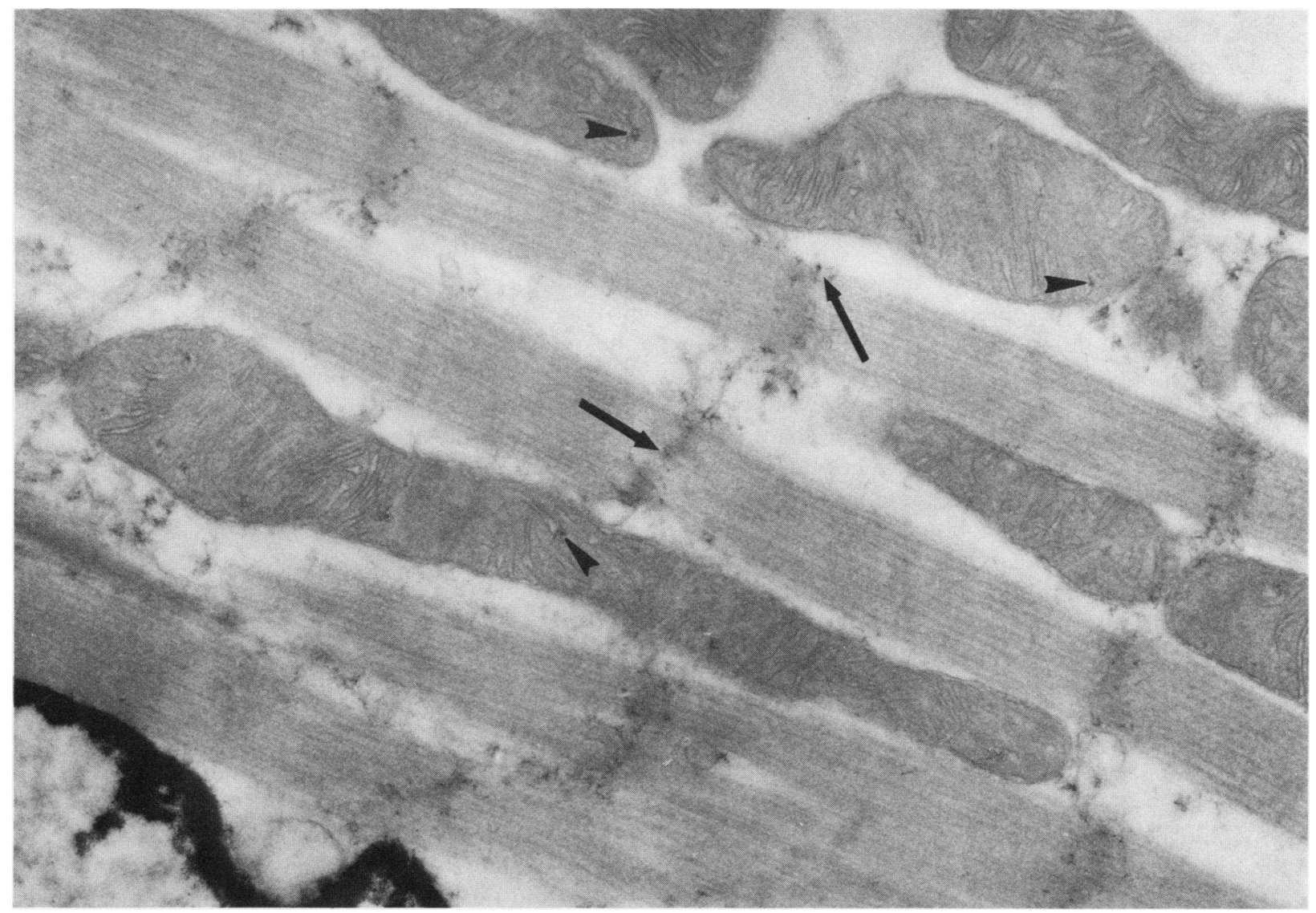

FIGURE 10 TEM of unstained, osmicated section reoxygenated for $1 \frac{1}{2}$ after $2 \mathrm{~h}$ of hypoxia. The muscle was exposed to La during the last hour of reoxygenation. The muscle shows evidence of damage in the form of edema, glycogen depletion, and absence of normal dense mitochondrial granules. Intracellular La is evident along the I bands of myofibrils (arrows) and in mitochondria (arrowheads). $\times 41,200$. 
in calcium balance and other possible changes in cellular homeostasis $(15-19,34)$, the typical finding in ultrastructural studies has been that lanthanum treatment is not associated with ultrastructurally demonstrable intracellular lanthanum deposition in completely normal myocardium (17-21). Intracytoplasmic lanthanum deposits, however, are readily demonstrable after removal of sialic acid from the plasma membrane-basal lamina complex of cardiac muscle cells by treatment with purified neuraminidase (18). These ultrastructural observations do not completely exclude the possibility that small amounts of lanthanum may enter normal muscle cells, but they do indicate that a normal plasma membrane-basal lamina complex serves as a barrier to major intracellular lanthanum deposition. In the present study, readily demonstrable abnormal intracellular lanthanum deposition commenced at a stage of hypoxic injury which followed clearly reversible events in myocardial injury (35-38) including defective excitationcontraction coupling, electrolyte shifts, and prompt depression in contractile parameters, indicating that early permeability changes are not detected by the lanthanum probe technique. These observations suggest that abnormal intracellular accumulation of lanthanum is related to an advanced stage of altered membrane permeability. Conversely, abnormal lanthanum accumulation commenses before the development of actual structural defects in membrane integrity and evidence of irreversible injury.

Other factors in addition to increased membrane permeability may be involved in ultrastructural visualization of lanthanum in damaged muscle cells. Our analytical electron microscopic findings showed that sites of intracellular as well as extracellular lanthanum accumulation also contained abundant phosphorus suggesting that the ultrastructurally demonstrable deposits may represent precipitates with high lanthanum and phosphate content. These precipitates formed without exposure of the muscles to phosphoruscontaining solutions. Intracellular deposition of lanthanum following hypoxic injury may have been facilitated by formation of inorganic phosphate upon hydrolysis of high energy phosphates. Other physicochemical alterations induced by hypoxia also could have contributed to intracellular lanthanum deposition. Cells with significant high energy phosphate reduction and elevated inorganic phosphate content also would be likely to have membrane permeability alterations related to inhibition of energy dependent membrane transport systems. Thus, the phenomenon of abnormal intracellular lanthanum deposition may be both directly and indirectly related to altered membrane function at a specific stage in the evolution of muscle injury. Less prominent lanthanum deposi- tion in very severely injured cells subjected to $2-3$ $h$ of hypoxia could have been related to loss of inorganic phosphate from such cells or other factors leading to decreased binding affinity of lanthanum or from decreased local concentration of lanthanum due to edema or washout of the lanthanum during specimen preparation. This phenomenon did not preclude use of the ionic lanthanum probe technique for establishing the relationship between cellular alterations related to abnormal membrane function and the transition from reversible to irreversible injury at an earlier stage in the evolution of damage.

Our data shows that abnormal lanthanum deposition occurred selectively at certain sites that have high affinity for calcium accumulation, including the I bands of myofibrils (39) and the inner mitochondrial membrane and adjacent matrix of the inner mitochondrial compartment $(5,6,40-43)$.Failure to detect calcium or cations other than lanthanum at these sites may be related to differences between lanthanum and other cations in local concentration, degree of tissue binding, and magnitude of loss during tissue preparation. The major reason, however, may be displacement of calcium by lanthanum, which has greater affinity for calcium binding sites (14-19). The distinctive accumulation of lanthanum in the mitochondria suggests that the lanthanum probe technique may have detected an abnormality in inner mitochondrial membrane function leading to increased cation transport and accumulation of cations in mitochondria $(5,6$, 40-43). A similar type of calcium deposition occurs in myocardium subjected to temporary coronary occlusion for $\mathbf{4 5} \mathrm{min}$ but fails to occur when occlusion is maintained for $90 \mathrm{~min}$ before reperfusion (41); this late failure of mitochondrial calcium accumulation develops independently of the "no reflow" phenomenon (41). These findings may be contrasted with results of biochemical studies with isolated normal mitochondria which showed that lanthanum blocks active membrane transport of calcium without interfering with other functions of normal mitochondria $(44,45)$. The timing of abnormal lanthanum accumulation during myocardial injury provides support for the hypothesis that, under certain conditions, marked intracellular calcium accumulation can trigger the progression to irreversible injury (46-48).

The phenomenon of abnormal transport and deposition of lanthanum and calcium by mitochondria does not appear to be directly related to alterations in the normal osmiophilic mitochondrial granules. The nature of the normal osmiophilic granules has not been definitely determined, and conflicting evidence has been presented regarding the possible role of these granules as normal storage sites of calcium or magnesium $(5,6,13,40,43,49-51)$. Available data sug- 
gests that the major component of these granules is organic osmiophilic material, possibly rich in phospholipids $(13,43,51)$.

Thus, the present study has characterized altered cellular and membrane pathophysiologies which apparently develop at a critical stage in the evolution of irreversible muscle injury. Jennings (1) and Willerson et al. (7) have proposed that the transition from reversible to irreversible injury is mediated by a critical defect involving the plasma membrane. Conversely, Trump et al. $(5,6)$ have suggested that the primary event in irreversible injury consists of significant damage to the inner mitochondrial membrane possibly resulting from activation of a calcium-dependent phospholipase after solubilization of mitochondrial calcium. Further work is required to determine if the primary defect occurs at the inner mitochondrial membrane or at the plasma membrane. The present study, however, suggests that severe functional defects of both the plasma membrane and mitochondrial membranes precede the development of irreversible injury. This data provides further support for the hypothesis that severe alterations of membrane function are of key importance in the evolution of irreversible injury.

\section{REFERENCES}

1. Jennings, R. B. 1976. Relationship of acute ischemia to functional defects and irreversibility. Circulation. 53 (Suppl. I): I-26-I-29.

2. Williamson, J. R., S. W. Schaffer, C. Ford, and B. Safer. 1976. Contribution of tissue acidosis to ischemic injury in the perfused rat heart. Circulation. 53 (Suppl. I): I-3I-14.

3. Hoffstein, S., G. Weissmann, and A. C. Fox. 1976. Lysosomes in myocardial infarction: studies by means of cytochemistry and subcellular fractionation, with observations on the effects of methyl-prednisolone. Circulation. 53 (Suppl. I): I-34-I-40.

4. Decker, R. S., A. R. Poole, E. S. Griffin, J. T. Dingle, and K. Wildenthal. 1977. Altered distribution of lysosomal cathepsin D in ischemic myocardium. J. Clin. Invest. 59: $911-921$.

5. Trump, B. F., I. K. Berezesky, V. Collan, M. W. Kahng, and W. J. Mergner. 1976. Recent studies on the pathophysiology of ischemic cell injury. Beitr. Pathol. 158: 363-388.

6. Trump, B. F., W. J. Mergner, M. W. Kahng, and A. J. Saladino. 1976. Studies on the subcellular pathophysiology of ischemia. Circulation. 53 (Suppl. I): I-17-I-26.

7. Willerson, J. T., F. Scales, A. Mukerjee, M. R. Platt, G. H. Templeton, G. C. Fink, and L. M. Buja. 1977. Abnormal myocardial fluid retention as an early manifestation of ischemic injury Am. J. Pathol. 87: 159-188.

8. Tyberg, J. V., L. A. Yeatman, W. W. Parmley, C. W. Urschel, and E. H. Sonnenblick. 1970. Effects of hypoxia on mechanics of cardiac contraction. Am. J. Physiol. 218: 1780-1788.

9. Bing, O. H. L., W. W. Brooks, and J. V. Messer. 1976. Prolongation of tension on reoxygenation following myocardial hypoxia: a possible role for mitochondria in muscle relaxation. J. Mol. Cell. Cardiol. 8: 205-215.

10. Apstein, C. S., O. H. L. Bing, and H. L. Levine. 1976. Cardiac muscle function during and after hypoxia: effects of glucose concentration, mannitol and isoproterenol. J. Mol. Cell. Cardiol. 8: 627-640.

11. Willerson, J. T., J. S. Crie, R. C. Adock, G. H. Templeton, and $\mathrm{K}$. Wildenthal. 1974. Influence of calcium on the inotropic actions of hyperosmotic agents, norepinephrine, paired electrical stimulation, and treppe. $J$. Clin. Invest. 54: 964-975.

12. Taubert, K., G. H. Templeton, J. T. Willerson, and W. Shapiro. 1976. Effects of digitalis and calcium on papillary muscles in normal and hypoxic states. Am. J. Physiol. 231: 66-72.

13. Goldstein, M. A., P. T. Thyrum, D. L. Murphy, J. H. Martin, and A. Schwartz. 1977. Ultrastructural and contractile characteristics of isolated papillary muscle exposed to acute hypoxia. J. Mol. Cell. Cardiol. 9: 285-295.

14. Lettvin, J. Y., W. F. Pickard, W. S. McCulloch, and W. Pitts. 1964. A theory of passive ion flux through axon membranes. Nature (Lond.). 202: 1338-1339.

15. Weiss, G. B. 1974. Cellular pharmacology of lanthanum. Annu. Rev. Pharmacol. 14: 343-354.

16. Sanborn, W. G., and G. A. Langer. 1970. Specific uncoupling of excitation and contraction in mammalian cardiac tissue by lanthanum. Kinetic studies. J. Gen. Physiol. 56: 191-217.

17. Langer, G. A., and J. S. Frank. 1972. Lanthanum in heart cell culture. Effect on calcium exchange correlated with its localization. J. Cell Biol. 54: 441-455.

18. Langer, G. A., J. L. Frank, L. M. Nudd, and K. Seraydarian. 1976. Sialic acid: effect of removal on calcium exchangeability of cultured heart cells. Science (Wash. D. C.). 193: 1013-1015.

19. Martinez-Palomo, A., D. Benitez, and J. Alanis. 1973. Selective deposition of lanthanum in mammalian cardiac cell membranes. Ultrastructural and electrophysiological evidence. J. Cell Biol. 58: 1-10.

20. Revel, J. P., and M. J. Karnovsky. 1967. Hexagonal array of subunits in intercellular junctions of the mouse heart and liver. J. Cell Biol. 33: C7-C12.

21. Shea, S. M. 1971. Lanthanum staining of the surface coat of cells. Its enhancement by the use of fixatives containing alcian blue or cetylpyridinium chloride. J. Cell Biol. 51: 611-620.

22. Hayat, M. A. 1970. Principles and Techniques of Electron Microscopy. Biological Applications. Van Nostrand Reinhold Company, New York. I: 1-412.

23. Hagler, H. K., K. P. Burton, R. H. Browne, R. C. Reynolds, G. H. Templeton, J. T. Willerson, and L. M. Buja. 1977. Energy dispersive X-ray spectroscopic (EDS) analysis of small particulate inclusions in hypoxic and ischemic myocardium. Proceedings of the IIT Research Institute Scanning Electron Microscopy Symposium 1977. Chicago Press Corporation. II: 145-152.

24. Somlyo, A. P., A. V. Somlyo, C. E. Devine, P. D. Peters, and T. A. Hall. 1974. Electron microscopy and electron probe analysis of mitochondrial cation accumulation in smooth muscle. J. Cell Biol. 61: 723-742.

25. Shuman, H., A. V. Somlyo, and A. P. Somlyo. 1976. Quantitative electron probe microanalysis of biological thin sections: methods and validity. Ultramicroscopy. 1: 317339.

26. Fawcett, D. W., and N. S. McNutt. 1969. The ultrastructure of the cat myocardium. I. Ventricular papillary muscle. J. Cell Biol. 42: 1-45. 
27. Fahimi, H. D., and R. S. Cotran. 1971. Permeability studies in heat-induced injury of skeletal muscle using lanthanum as fine structural tracer. Am. J. Pathol. 69: 143-157.

28. Hoffstein, S., D. E. Gennaro, A. C. Fox, J. Hirsch, F. Streuli, and G. Weissmann. 1975. Colloidal lanthanum as a marker for impaired plasma membrane permeability in ischemic dog myocardium. Am. J. Pathol. 79: 207-218.

29. Boutet, M., I. Hüttner, and G. Rona. 1976. Permeability alteration of sarcolemmal membrane in catecholamine-induced cardiac muscle cell injury: In vivo studies with fine structural diffusion tracer horseradish peroxidase. Lab. Invest. 34: 482-488.

30. Bandonnel, M. C., I. Hüttner, M. Boutet, and G. Rona. 1977. Microcirculatory factors in ischemic cardiac muscle cell injury as revealed by diffusion tracer horseradish peroxidase. Am. J. Pathol. 86: 42a-43a. (Abstr.)

31. Kent, S. P. 1966. Intracellular plasma protein: a manifestation of cell injury in myocardial ischemia. Nature (Lond.). 210: 1279-1281.

32. Kent, S. P. 1967. Diffusion of plasma proteins into cells: a manifestation of cell injury in human myocardial ischemia. Am. J. Pathol. 50: 623-637.

33. Kent, S. P. 1969. Diffusion of plasma proteins into cells: a manifestation of cell injury in rabbit skeletal muscle exposed to lecithinase C. Arch. Pathol. 88: 407-412.

34. Nayler, W. G., and J. P. Harris. 1976. Inhibition by lanthanum of the $\mathrm{Na}^{+}+\mathrm{K}^{+}$activated ouabain-sensitive adenosinetriphosphatase enzyme.J. Mol. Cell. Cardiol. 8: 811822.

35. Regan, T. J., M. A. Harman, P. H. Lehan, W. M. Burke, and H. A. Oldewurtel. 1967. Ventricular arrhythmias and $\mathrm{K}^{+}$ transfer during myocardial ischemia and intervention with procaine amide, insulin or glucose solution. $J$. Clin. Invest. 46: 1657-1668.

36. Sybers, H. D., P. R. Helmer, and Q. R. Murphy. 1971. Effects of hypoxia on myocardial potassium balance. Am. J. Physiol. 220: 2047-2050.

37. Nayler, W. G., J. Stone, V. Carson, and D. Chipperfield. 1971. Effect of ischaemia on cardiac contractility and calcium exchangeability. J. Mol. Cell. Cardiol. 2: $125-143$

38. Meerbaum, S., T. W. Lang, R. Corday, S. Rubins, S. Hirose, C. Costantini, H. Gold, and M. Dalmastro. 1974. Progressive alterations of cardiac hemodynamic and regional metabolic function after acute coronary occlusions. Am. J. Cardiol. 33: 60-68.
39. Legato, M. J., and G. A. Langer. 1969. The subcellular localization of calcium ion in mammalian myocardium. J. Cell Biol. 41: 401-423.

40. Reynolds. E. S. 1965. Liver parenchymal cell injury. III. The nature of calcium-associated electron-opaque masses in rat liver mitochondria following poisoning with carbon tetrachloride. J. Cell Biol. 25: 53-75.

41. Kloner, R. A., C. E. Ganote, and R. B. Jennings. 1974. The "no reflow" phenomenon after temporary coronary occlusion in the dog. J. Clin. Invest. 54: 1496-1508.

42. Jennings, R. B., and C. E. Ganote. 1976. Mitochondrial structure and function in acute myocardial ischemic injury. Circ. Res. 38 (5 Suppl. I): I-80-I-91.

43. Carafoli, E., and M. Crompton. 1976. Calcium ions and mitochondria. Symp. Soc. Exp. Biol. XXX: 89-115.

44. Mela, L. 1969. Inhibition and activation of calcium transport in mitochondria. Effect of lanthanides and local anesthetic drugs. Biochemistry 8: 2481-2486.

45. Lehninger, A. L., and E. Carafoli. 1971. The interaction of $\mathrm{La}^{3+}$ with mitochondria in relation to respirationcoupled $\mathrm{Ca}^{2+}$ transport. Arch. Biochem. Biophys. 143: 506-515.

46. Fleckenstein, A., J. Janke, H. J. Döring, and D. Leder. 1974. Myocardial fiber necrosis due to intracellular Ca overload-a new principle in cardiac pathophysiology. Recent Adv. Stud. Card. Struct. Metab. 4: 563-580.

47. Reimer, K. A., J. E. Lowe, and R. B. Jennings. 1977. Effect of the calcium antagonist verapamil on necrosis following temporary coronary artery occlusion in dogs. Circulation. 55: 581-587.

48. Wrogemann, K., and S. D. J. Pena. 1976. Mitochondrial calcium overload: A general mechanism for cell necrosis in muscle diseases. Lancet. I: 672-674.

49. Somlyo, A. V., J. Silcox, and A. P. Somlyo. 1975. Electron probe analysis and cryoultramicrotomy of cardiac muscle: Mitochondrial granules. In Proceedings of ThirtyThird Annual Meeting of the Electron Microscopy Society of America. G. W. Bailey and C. J. Arcenaux, editors. Claitor's Publishing Division, Baton Rouge, Louisiana. 532-533.

50. Pasquali-Ronchett, I., J. W. Greenawalt, and E. Carafoli. 1969. On the nature of the dense matrix granules of normal mitochondria. J. Cell Biol. 40: 565-568.

51. Barnard, T., and B. A. Afzelius. 1972. The matrix granules of mitochondria: A review. Sub-Cell. Biochem. 1: 375389. 